\title{
Modelling sulphur dioxide levels of Konya city using artificial intelligent related to ozone, nitrogen dioxide and meteorological factors
}

\author{
S. Dursun ${ }^{1,2} \cdot$ F. Kunt ${ }^{1} \cdot$ O. Taylan $^{2}$
}

Received: 17 April 2014/Revised: 10 February 2015/Accepted: 21 April 2015/Published online: 3 June 2015

(C) Islamic Azad University (IAU) 2015

\begin{abstract}
Increasing industrial developments increased the environmental pollution problems in many cities of the world. Air quality modelling and indexes are used to introduce the information on local air quality indicators in polluted regions. Estimation and monitoring of air quality in the city centres are important due to environmental health and comfort of human-related topics. Air quality approximation is a complicate subject that artificial intelligent techniques are successfully used for modelling the complicated and nonlinear approximation problems. In present study, artificial neural network and an adaptive neuro-fuzzy logic method developed to approximate the impact of certain environmental conditions on air quality and sulphur dioxide pollution level and used with this study in Konya city centre. Data of sulphur dioxide concentrations were collected from 15 selected points of Konya city for prediction of air quality. Using air quality standards, air quality was discussed by considering the sulphur dioxide concentration as independent variables with meteorological parameters. Different meteorological parameters were used for investigation of pollution relation. One of the important modelling tools, adaptive network-based fuzzy inference system model, was used to assess performance by a number of checking data collected from different sampling stations in Konya. The outcomes of adaptive network-based fuzzy inference system model was evaluated by fuzzy quality
\end{abstract}

S. Dursun

sdursun@selcuk.edu.tr

1 Environmental Engineering Department, Engineering Faculty, Selcuk University, Selcuklu, 42003 Konya, Turkey

2 Department of Industrial Engineering, Faculty of Engineering, King Abdulaziz University, P. O. Box 80204, Jeddah 21589, Saudi Arabia charts and compared to the results obtained from Turkey and Environmental Protection Agency air quality standards. From the present results, fuzzy rule-based adaptive network-based fuzzy inference system model is a valuable tool prediction and assessment of air quality and tends to propagate accurate results.

Keywords Air pollution - Air quality - Artificial neural network · Environment · Fuzzy logic

\section{Introduction}

Air pollution is the increasing problem in metropolitan cities of many countries with increasing population, the fast industrial development, requirement of high-energy demand and disorderly urbanization. Air pollution level also increases in the urban area depending on many environmental reasons and conditions on some special days. Climatic factors and energy production/usage are main factors on urban air quality as a combination and integration of the following factors: air pollution, meteorological conditions (Öztürk et al. 2013; Taylan 2013b). Researchers are investigating to explain air pollution and related natural and artificial factors. Recently, some intelligence techniques have been put foreword by various researches with interrelation of air pollution and many factors to propose as alternatives to general statistical comparison in allot of scientific disciplines as well as environmental pollution.

Kadiyala and Kumar (2012) provided a comprehensive review of all the existing statistical performance measures, summarized the mathematical equations on computing the various statistical performance measures and systematically ranked the performance measures, with emphasis on the extreme-end (peak-end/low-end) and the mid-range 
contaminant concentrations. The study established and proposed an independent set of the ranked primary and secondary performance measures criteria that are to be used in the operational model evaluation of the outdoor and IAQ models. The ranking methodology is based on the properties of different statistical performance measures and information from prior studies in the literature.

Artificial neural networks (ANN) are considered to be simplifying the mathematical models of human neural systems (Deutsch et al. 2008; Zounemat-Kermani and Scholz 2013; Fallahpour and Moghassem 2013). Neural networks are generally training the raw data, and for generalization of the structure, it can be learned as new associations, new functional dependencies and new patterns. This situation has been used widely for modelling and forecasting many sorts of data. Multilayer perceptron has been applied particularly within the field of air quality prediction in the recent investigations. Scientists (Rani and Govardhan 2013) have put forth similar researches on the atmospheric contrition with the applications of ANN. Air pollutants were modelled by using ANN models by various researchers: $\mathrm{SO}_{2}$ (Chelani et al. 2002; Yıldırım and Bayramoglu 2006; Cacciola et al. 2013; Savic et al. 2013), nitrogen oxides (Perez and Trier 2001), ozone (Jorquera et al. 1998; Gardner and Dorling 2000) and particulate matters (Perez et al. 2000; Ordieres et al. 2005; Taylan 2013a; Alkasassbeh et al. 2013).

New artificial intelligence techniques have been improved, under the name of soft computing to aim at integrating powerful artificial intelligence methodologies, such as neural networks and fuzzy inference systems (Taylan 2013b). Fuzzy logic performs an inference mechanism under cognitive uncertainty, and neural networks possess exciting capabilities such as learning, adaptation, fault tolerance, parallelism and generalization of data sets. It may incorporate the concept of fuzzy logic into the neural networks to enable a system to deal with cognitive uncertainties in a manner more like humans. Hybrid system results are called a neuro-fuzzy network (Fuller 1995; Taylan 2013b). Adaptive neuro-fuzzy inference system (ANFIS) is claimed as a universal approximation to represent high nonlinear functions more powerfully than conventional statistical methods (Jang et al. 1997a, b; Rawat and Burse 2013; Moumeni et al. 2013).

Therefore, a number of studies have been performed to develop new air quality indexes using fuzzy inference system. For example, in a study performed by Onkal-Engin et al. (2004), an air quality index was developed based on fuzzy inference system, which produced significant results. In another study carried out by Khan and Sadiq (2005), the sensitivity of receptors was also included in an air quality index, which produced better estimation of air quality impact on human health. In a study conducted by Hájek and Olej (2009), criteria air pollutants as well as meteorological parameters were included in the air quality index, using fuzzy inference system. The results suggest that fuzzy logic is a suitable tool for air quality assessment (Sowlat et al. 2011).

Curtis et al. (2006) pointed that atmospheric pollutants linked too many types of health problems of many body systems including the respiratory, cardiovascular, immunological, haematological, neurological and reproductive/developmental systems. On the other hand, Barnett et al. (2006) determined that higher airborne levels of $\mathrm{PM}_{10}, \mathrm{PM}_{2.5}, \mathrm{NO}_{2}$ and $\mathrm{SO}_{2}$ were all associated with significantly higher rates of childhood hospital admissions for pneumonia and acute bronchitis. Romieu et al. (1992) and Zemp et al. (1999) stated that significantly higher levels of chronic cough and phlegm production have been found in children exposed to higher ambient $\mathrm{SO}_{2}$ levels and in adults exposed to higher ambient $\mathrm{PM}_{10}$ levels. Inhaling such fine sand can cause a syndrome called Al Eskan disease, which involves a variety of respiratory and immunological problems.

The two main sources of pollutants in urban areas are transportation (predominantly automobiles) and fuel combustion in stationary sources, including residential, commercial, and industrial heating and cooling. Motor vehicles produce high levels of carbon monoxides (CO) and a major source of hydrocarbons (HC) and nitrogen oxides (NOx), whereas fuel combustion in stationary sources is the dominant source of sulphur dioxide $\left(\mathrm{SO}_{2}\right)$. Several researchers have proposed different techniques to predict the pollution including application of neuro-fuzzy. The techniques of artificial intelligence based in fuzzy logic and neural networks have been frequently applied together. The reasons to combine these two paradigms come out of the difficulties and inherent limitations of each isolated paradigm. Soni and Shukla (2012) have also discussed the scheme for the prediction of $\mathrm{O}_{3}$ based on $\mathrm{NO}_{2}$ and $\mathrm{SO}_{2}$ measurements.

$\mathrm{SO}_{2}$ is prevalent in most industrial raw materials, including crude oil, coal and common ores like aluminium, copper, zinc, lead and iron. Sulphur gases are produced when fuel, such as oil and especially coal, is burned, during mining and industrial processes, e.g. when petrol is extracted from crude oil and naturally from volcanic eruptions. Health effects of $\mathrm{SO}_{2}$ gas are irritation to the eyes and respiratory system, reduced pulmonary functions and aggravation to respiratory diseases such as asthma, chronic bronchitis and emphysema. Exposure to extremely high concentrations will cause permanent damage to the respiratory system as well as extreme irritation to the eyes (due to production of dilute sulphuric acid around the eyes). When $\mathrm{SO}_{2}$ reacts with other chemicals in the air to form tiny sulphate particles, these may also be inhaled in which case they gather in the lungs and are associated with 
increased respiratory symptoms and disease, difficulty in breathing and premature death.

Population growth together with high rate of urbanization, industrialization and increased fossil fuels usage for transportation and heating system in winter period has increased concentration of various air gaseous, e.g. hydrocarbons, nitrogen and sulphur dioxides (Goyal et al. 2006; Khare and Nagendra 2007; Dursun et al. 2012). The number of factories in Konya is over one thousand, and number of employees are 100,000 in the industrial sector (Güçlü and Dursun 2010). The air quality around industrial region of Konya city was studied by researchers (Güçlü and Dursun 2010; Kunt and Dursun 2012), and they found that the main pollutants released from the industrial sector are particle matter, hydrocarbons, nitrogen and sulphur dioxides. Temperature is one of the most significant meteorological variables influencing air quality in urban atmospheres as it directly affects gas and heterogeneous chemical reaction rates and gas-to-particle partitioning (Aw and Kleeman 2003).

The aim of this study is to focus on time series of the crustal-related species and the reconstructed sulphur dioxide concentration in air sampling from March 2011 to January 2012 period in Konya city centre (Turkey). This information will provide a baseline to examine trends and has implications for controlling effectiveness of local sulphur dioxide. The potential of sulphur dioxide emissions has been reported for passing years. This study aims to estimate air pollution concentration and its impact on human health in Konya and to put forward air quality planning to prepare data for the air quality levels with much cleaner ambient air. For the previously mentioned purpose, passive sampling method has been used as a simple operation measurement method because it needs no electric power for sampling and it is easily portable and inexpensive option, especially in the winter time period, when an intense air pollution will happen depending on meteorological conditions, to be determined in advance and to reduce the impact of air pollution contributing significantly. Thus, air pollution modelling and earlier prediction studies are very important. In this study, atmospheric levels of $\mathrm{NO}_{2}, \mathrm{SO}_{2}$ and ozone will be estimated with new applications such as artificial neural networks and fuzzy logic models preparation programs for modelling and forecasting instead of classic statistical methods to compare the values with highly successful results.

\section{Materials and method}

\section{Study area}

The Konya plain has been grounded in the south area of Middle Anatolia, which has been centred in Anatolian
Peninsula. It has been surrounded by mountains that have $1016 \mathrm{~m}$ average height. The south part of it is included by Mediterranean. Konya is geographically placed between $36^{\circ} 41^{\prime}$ and $39^{\circ} 16^{\prime}$ north latitudes with $31^{\circ} 14^{\prime}$ and $34^{\circ} 26^{\prime}$ east longitudes. Toros Mountains surround the city from the quarters of south-east, south and south-west. Topography of the Centrum begins to rise up clearly against to west, closed to Meram, which has been placed in the west part of the city frontiers in $1250 \mathrm{~m}$. When you look around this plain, it will be seen that the cross section of this bent down plane which lies down in a direction of north to south has been placed on a clear line and these slopes of hills are forming a wall in west side of Konya. Elevations are Dereköy and Loras Mountains $2050 \mathrm{~m}$ inside in the west. Çal Mountain is situated $1750 \mathrm{~m}$ west of these mountains. In the north side of the city, there are slopes of hills that constitute shortest walls aspect from east to west side. This line turns towards north again while it ends with the hill that has been placed in Karaömerler village.

In Konya, there are different climate systems because of its geographic position. It has placed trough the north-south way including a wide area. Konya does not have stormy weather. However, in spring there is much more wind than in other seasons. It blows mostly from north-northeast and northeast. The wind is carrying an importance because when the blow increased air pollution decreases. It has horizontal air action that carries pollution and rates.

In Konya, winters have high pressure. Konya city is affected by the meteorological systems coming from north Balkans and south Mediterranean Sea. Pressure has some difference according to gravity and seasons. In addition, it can change according to frontier passes that is placed in atmosphere and heat. In summer, Konya does not have fog. Fog comes from the stratus clouds that get down to surface. Moisture increases when there is fog and the heat comes up to air. Konya has the fog in limits in December. In Centrum, the less moisture seems in July, and the most of moisture seems in December and January. Because of its geographic place, Konya has a different climate against north to south. Temperature changes every season. In January, average heat is -0.2 ; in July, the average heat is $24^{\circ}$. In city, because of the hard climate rules, cold, rain and wind are effective in winter and spring. In winter snow and rain and in spring, downpour and thunder with hail are the most effective ones. It rain the maximum in February.

\section{Data collection and data analyse method}

This study was performed representing the data for four sampling periods at each season set using passive sampler measurement method performed at 15 different sampling points to determine Konya air pollutants, and total of 60 data sets have been collected. The schools for selecting 
sampling points of the city's air quality have been noted as being in different regions as high, low and average pollution levels regions. Location of the school, the region traffic density and region-warming shape were significant factors in the selection of sampling points (Fig. 1).

Selected points were marked on the map of Konya using ArcGIS 10.2 software program. Sample collection of $\mathrm{NO}_{2}$ and $\mathrm{SO}_{2}$ components was performed in Teflon sampler, and the ozone was collected in a separate different sampler made in plastic materials $\left(\right.$ Delrin $\left.^{\circledR}\right)$. Passive samplers have $2 \mathrm{~cm}$ of inner diameter and $2.5 \mathrm{~cm}$ of height of 'badge' type samplers (Ozden 2005). These samplers were improved by Bertoni et al. (2000) the first time in order to determine the BTX (benzene, toluene, xylene), and passive samplers were developed modifying from the under name of ANALYST ${ }^{\circledR}$ granted patents (Yay et al. 2008).

Passive samplers placed in each sampling point are covered inside the protective shelter in order to minimize impact of facing down rain, wind, etc., factors such as measured on disposed in the open ends. In addition, at all sampling locations of sampler location (altitude, distances to source points, executive rooms instead of classrooms and the secure office, selecting places not very close trees, etc.), attention has been paid to have the same conditions. Preparation of $\mathrm{NO}_{2}, \mathrm{SO}_{2}$ and ozone passive samplers and analysis were performed at Anadolu University Environmental Engineering Department as mentioned below.

\section{Preparation and analysis of sampler}

TEA (20\% aqueous solution)-absorbed Whatman $\mathrm{GF} /$ filter papers were used for preparation of $\mathrm{NO}_{2}$ and $\mathrm{SO}_{2}$ samplers, and ozone sampler was prepared with $\mathrm{AA}$ $\left(1 \% \mathrm{NaNO}_{2}+2 \% \mathrm{Na}_{2} \mathrm{CO}_{3}+2 \%\right.$ glycerol $)$ with an aqueous solution. The dried filter paper samplers were fixed with 5-mm-thick rings to the base of the samplers and the lid closed until to use it. After a 1-week sampling period, tidy capped samples were collected from the sampling points and brought to the laboratory, and Dionex Ion Chromatography ${ }^{\circledR} 2500$ device (IC) was used for secondary analyses. Prior to analysis, examination materials from the sampling filter paper was extracted using $10 \mathrm{ml}$ of ultrapure water (Milli-Q) $+0.3 \mathrm{ml}$ of $35 \%$ $\mathrm{H}_{2} \mathrm{O}_{2}$ for $\mathrm{NO}_{2}-\mathrm{SO}_{2}$, and 15 min with $5 \mathrm{ml}$ of ultrapure water for ozone samples. The analysis was performed for identification of according $\mathrm{NO}_{2}$ component as $\mathrm{NO}_{2}^{-1}, \mathrm{SO}_{2}$ component as $\mathrm{SO}_{4}^{-2}$ and ozone as $\mathrm{NO}_{3}^{-1}$ ions designated ion concentrations $\left(\mathrm{mg} \mathrm{ml}^{-1}\right)$, and then, $\mathrm{NO}_{2}^{-}, \mathrm{SO}_{4}^{-2}$ and

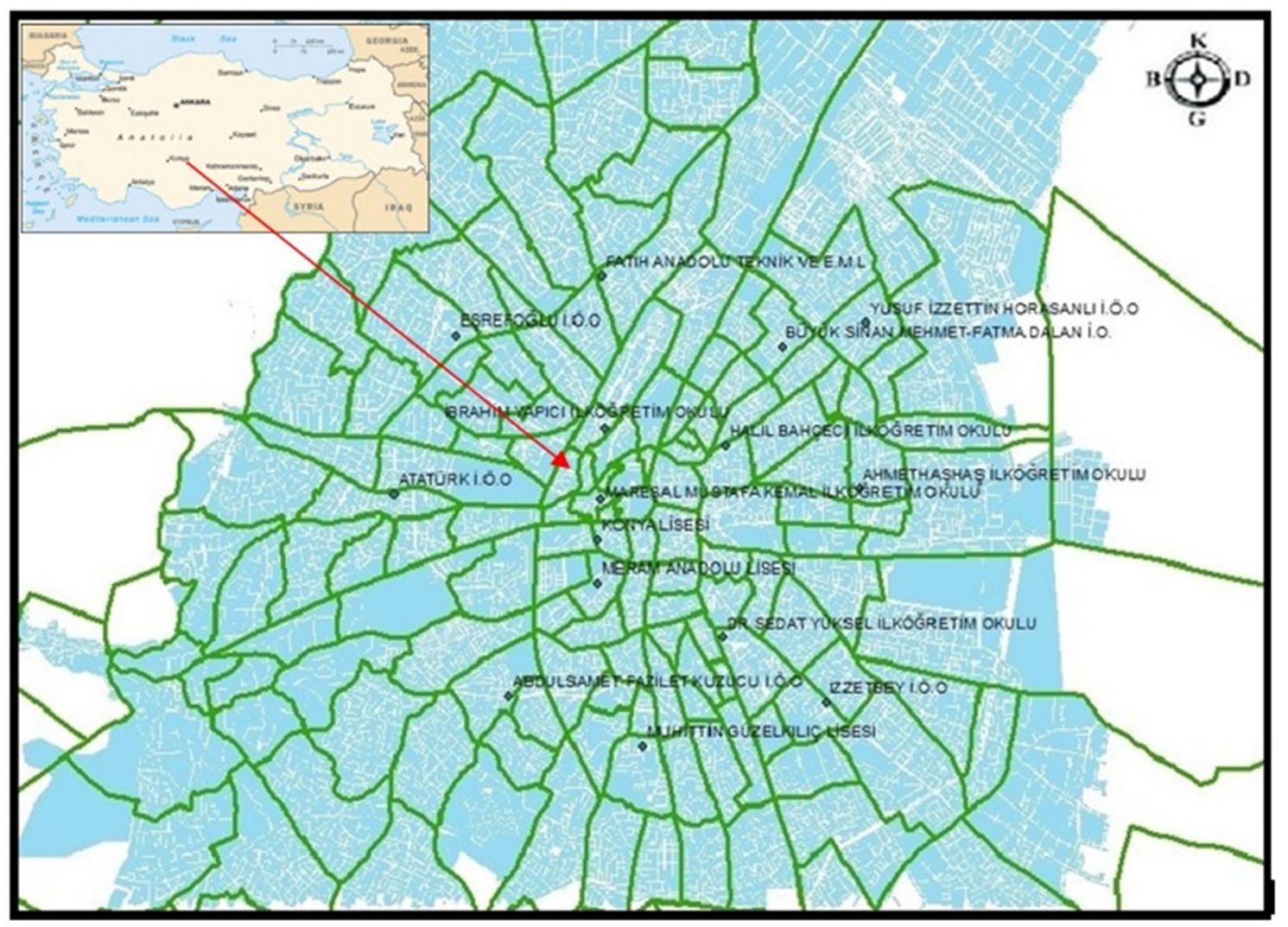

Fig. 1 Location of study area and selected points for passive sampling 
$\mathrm{NO}_{3}{ }^{-}$amount (as $\mathrm{mg}$ ) was calculated using extraction volume and sampling time period. Then, calculated $\mathrm{mg}$ values were converted to atmospheric $\mathrm{NO}_{2}, \mathrm{SO}_{2}$ and ozone concentrations $\left(\mathrm{mg} \mathrm{m}^{-3}\right)$ using Fick's First Law.

\section{Collections of meteorological parameters}

Meteorological parameters such as atmospheric pressure, temperature, wind speed, relative humidity and precipitation were measured using Oregon Scientific WMR200A Meteorology equipment. The number of meteorological data measured by our equipment is same as the number of pollution parameters (60 data sets) and these measured data were compared with measurements of the Konya 8th Regional Meteorological Directorate represent in order to determine whether represent the Konya province. It is observed that the results show similarity. However, for the calculating necessary average temperature value for all the points, data of Konya 8th Meteorological Regional Directorate were used.

\section{Modelling by artificial intelligence methods}

\section{Artificial neural networks (ANNs)}

Lin and Lee (1996) stated that artificial neural networks (ANNs) were systems that were constructed to make use of some organizational principles resembling the human brain. ANNs are computing systems that are made up of a number of simple highly interconnected signals or information processing units. In this study, the back-propagation multilayer perceptron (BPMLP) algorithm was used for the estimation of $\mathrm{SO}_{2}$ concentration in Konya. The BPMLP is supposed to perform a specific nonlinear mapping, which can be expressed in terms of a given set of examples. The learning process of the this algorithm is the adaptation of all synaptic weights in such a way that the discrepancy between the actual output signals and the desired signals would be as small as possible, when they are averaged for over all the learning samples. The standard BPMLP algorithm uses the steepest descent algorithm to minimize the mean squared error of given data using the function given below. The error function for the $p$ th sample is presented in Eq. 1.

$E_{p}=\frac{1}{2} \sum_{j=1}^{n_{3}}\left(d_{j p}-y_{j p}\right)^{3}=\frac{1}{2} \sum_{j=1}^{n_{3}} e_{j p}^{2}$

where $e_{j p}, d_{j p}$ and $y_{j p}$ are the squared error, desired output and the actual output for the $p$ th learning sample, respectively. The global error function can be summed for over all learning samples and can be presented for the input layer as it is given in Eq. 2.
$E_{\text {total }}=\sum_{p} E_{p}=\frac{1}{2} \sum_{p} \sum_{j} e_{j p}^{2}$

In this study, an online algorithm was used to update the weights. The algorithm for each learning sample was presented as an input; all weights were updated before the next learning sample was presented. All the synaptic weights $w_{j i}$ were changed by the amount of $\Delta w_{j i}$ given in Eq. 3.

$\Delta w_{j i}=-\eta \frac{\partial E_{p}}{\partial w_{j i}}, \quad \eta>0$

where $\eta$ is the learning parameter. On the other hand, an updated formula can be derived for the weights, as it is given in Eq. 4.

$\Delta w_{j i}=\gamma \delta_{j} z_{i}$

where $\delta_{j}$ is the local gradient of the hidden neuron $j$, and $z_{i}$ is the function signal at the output of neuron ' $i$ '. This function signal $z_{i}$ at the output of neuron ' $i$ ' is obtained by passing the weighted sum of inputs to neuron ' $i$ ' from a nonlinear activation function. In this study, the activation function chosen is a unipolar sigmoid function that is presented in Eq. 5.

$x_{i}=\frac{1}{1+\exp \left(-c_{i} u_{i}\right)}$

where $c_{i}$ is a constant value. In Eq. $5, u_{i}$ is the weighted sum of the inputs to the neuron $i$, and for the first hidden layer it can be defined as it is given in Eq. 6 .

$u_{i}=\sum_{j=1}^{n_{0}} w_{i j} x_{j}+\theta_{i}$

where $\theta_{i}$ is a bias value, and $x_{j}$ is the $j$ th component of the input pattern. The local error of the internal hidden layer is determined based on the local errors at the upper layer. The highest output layer $\varphi_{j}$ was computed as a vector of the local gradient at the output layer of the $j$ th neuron. The formula for this calculation is presented in Eq. 7.

$\delta_{j}^{\text {out }}=\left(d_{j p}-y_{j p}\right) \frac{\partial \Psi_{j}^{\text {out }}}{\partial u_{j}^{\text {out }}} \quad \varphi_{j}=\left(d_{j}-y_{j}\right) \frac{\partial \Psi_{j}}{\partial u_{j}}$

where $\delta$ is the unipolar sigmoid function at the output layer? One way to improve the back-propagation multilayer learning algorithm is to smooth the weight changes by over relaxation. In other words, by adding the momentum term, it is defined as:

$\Delta w_{j i}(k)=\gamma \varphi_{j} z_{i}+\alpha \Delta w_{j i}(k-1)$

where $0 \leq \alpha \leq 1$ 
The second term in Eq. 8 is called the momentum term that makes the current $k$ th search direction an experimentally weighted average of past $(k-1)$ th directions. This term damps the effect of the learning parameter, $\gamma$ that may cause parasitic oscillations, which prevent the algorithm from converging to the desired solution. Hence, it enables the improvement of the convergence rate and the steady state performance of the backpropagation multilayer learning algorithm.

Artificial neural network structure and flow chart were prepared using seven parameters model in MATLAB Toolbox (Fig. 2).

\section{Adaptive network-based fuzzy interference system (ANFIS)}

A neuro-fuzzy model produces numerical outcomes and includes the following parameters: the input and output variables defined by linguistic statements, the fuzzy partition of the input and output spaces and the membership functions for the input and output variables, the fuzzy control rules, the inference mechanism including for fuzzy implication and compositional operators, and the defuzzification method (Sugeno and Takagi 1983). The main goal of developing an ANFIS model is to analyse the effect of certain parameters on $\mathrm{SO}_{2}$ as to provide online information and take immediate actions in a more intelligent way. The ANFIS model for this study contained five rules, with five MFs assigned to each input variable. The structure of an adaptive network is composed of nodes connected by directed links, where each node performs a function on its incoming signals to generate a single node output and each link specifies the direction of signal flow from one node to another (Jang et al. 1997a, b). The designed ANFIS architecture is composed of five nodes in input layer, four nodes $\left(\mathrm{H}_{1}-\mathrm{H}_{5}\right)$ in hidden layer and one node $\left(Z_{k}\right)$ in output layer. If $x_{1}$ is the air pressure, its fuzzy term set $T\left({ }_{X 1}\right)$ can be identified as very low, low, moderate, high\}. Hence, the output variable $Z_{k}$, referring to the sulphur dioxide $\left(\mathrm{SO}_{2}\right)$ can be presented by the linear functions. The ANFIS model developed for sulphur dioxide was established by five fuzzy rules. The output part of a fuzzy rule can be presented as it is given in Eq. 9.

$z_{n}=a_{n}\left(x_{1}\right)+b_{n}\left(x_{2}\right)+c_{n}\left(x_{3}\right)+\cdots+d_{n}\left(x_{7}\right)+r_{n}$

The overall output is the summation of all incoming parameters as is calculated by Eq. 10 .

$Z_{k}=\sum_{i} \bar{W}_{i} f_{i}=\frac{\sum_{i} w_{i} f_{i}}{\sum_{i} w_{i}}$

It is observed that when the premise parameters of rules are determined, the overall output can be expressed as a linear combination of the consequent parameters. The overall outcome $Z_{k}$ can be rewritten in terms of $z_{n}$ as it is given in Eq. 11.

$\begin{aligned} Z_{k}= & \bar{W}_{1}\left(a_{1} x_{1}+b_{1} x_{2}+c_{1} x_{3}+d_{1} x_{4}+e_{1} x_{5}+g_{1} x_{6}+h_{1} x_{7}\right. \\ & \left.+r_{1}\right)+\cdots+\bar{W}_{5}\left(a_{5} x_{1}+b_{5} x_{2}+\cdots+h_{5} x_{7}+r_{5}\right)\end{aligned}$

where $W$ s are the weights of the MFs of the fuzzy sets, respectively. For instance, $w_{1}$ denotes the degree of compatibility between the MFs of sulphur dioxide and fuzzy set 'low and average'. On the other hand, Nie (1995) stated that fuzzy reasoning is an inference procedure that derives conclusions from a set of fuzzy if-then rules and known facts. In order to develop an ANFIS model, the input and the output parameters were determined and presented to the learning algorithm.

\section{Results and discussion}

Artificial neural networks (ANN) and fuzzy application were used in many researchers for simplifying the mathematical models similar to human neural systems. According to Kadiyala and Kumar (2013), the environmental output is modelled as a function of the input variables and validated. Reported environmental studies have adopted a variety of AI methods that included ANNs [back-
Fig. 2 Artificial neural network flowchart used in this investigation

Temperature ${ }^{\circ} \mathrm{C}$
Moisture (\%)
Wind speed $(\mathrm{m} / \mathrm{sec})$
Atm. Pressure $(\mathrm{hPa})$
Rainfall $(\mathrm{mm})$
$\mathrm{NO}_{2}\left(\mu \mathrm{g} / \mathrm{m}^{3}\right)$
Ozone $\left(\mu \mathrm{g} / \mathrm{m}^{3}\right)$

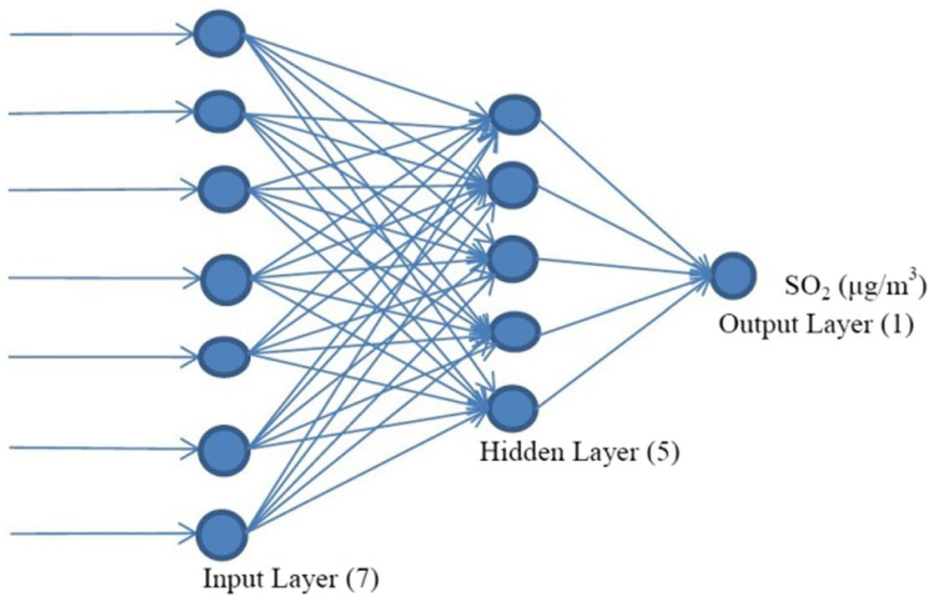


propagation networks (BPNs), radial basis function networks (RBFNs), feed-forward networks (FFN), etc.], fuzzy logic (FL) and genetic algorithms (GAs). The BPN is the most widely used ANN that follows a cyclic process of forward computation of the target environmental variables and backward computation of the error signals until a specified error criterion is reached. In the FFNs and the RBFNs, there is only the forward computation of environmental variables. The FL-modelling follows a rulebased approach where verbal definitions are provided instead of the governing physical relationships. GAs are optimization algorithms based on the mechanics of genetics. Kadiyala et al. (2013) developed a novel approach to modelling indoor air quality (IAQ) of a public transportation bus by the development of hybrid genetic-algorithmbased neural networks (also known as evolutionary neural networks) with input variables optimized from using the regression trees, referred as the GART approach.

\section{Measurement values of the pollutants}

In this study, the data for four different seasons collected by passive sampler measurement method at 15 different sampling points to determine Konya air pollution showed that pollution levels are not above $100 \mu \mathrm{g} \mathrm{m}^{-3}$ for $\mathrm{NO}_{2}$ and $150 \mu \mathrm{g} \mathrm{m}^{-3}$ for $\mathrm{SO}_{2}$ are well within the long-term air quality standards of Turkish government as HKDYY (2008). Summary of the measurement results is presented in Table 1. These data were used for neural network comparison and modelling.

\section{Artificial neural network model for $\mathrm{SO}_{2}$ prediction}

The training of neural network program occurred as follows; the training stopped when the validation error increased for five iterations, which occurred at iteration eleven. In this example, the result is reasonable because of the following considerations: The final mean-square error is small. The test set error and the validation set error have similar characteristics. No significant over-fitting has occurred by iteration six where the best validation performance has occurred.

Figure 3 shows the output tracks the targets for training $R$, testing $R$ and validation $R$; the value of $R$ value is 0.9972 for training, 0.206 for testing and 0.643 for validation, and on the other hand, the value of total response is 0.778 . To obtain accurate results, the initial network weights and biases were reset to new values and trained again.

\section{An adaptive neuro-fuzzy model for $\mathrm{SO}_{2}$ prediction}

The ANFIS model optimization method is a hybrid learning algorithm; in order to determine the number of rules and the membership functions, sub-clustering algorithm was employed. In this investigation, a total of 60 data sets for pollution parameters and 60 data sets for meteorological parameters were used. The data sets were divided into three parts; 42 data were used mainly for training the algorithm, 18 data were used for checking, and random 40 data were used for validation of the model. Fuzzy reasoning is an inference procedure deriving outcomes from a set of if-then rules and fact base. The fact base and rule base of a neurofuzzy model are a set of tools depicting the relations between input and output variables. As it appears in Fig. 4, the membership functions are typically defined on one-dimensional universes; however, as it is depicted in Fig. 5, they can be described on multidimensional universes too.

Figure 4 depicts the $\mathrm{SO}_{2}$ plotted in one-dimensional curves versus different parameters such as rainfall, $\mathrm{NO}_{2}$, temperature, air pressure. This membership value expresses the degree of membership that the specific combination of parameters in the $n$-dimensional space has in a particular fuzzy set defined on the universe of discourse. A nonlinear relation between input parameters and the $\mathrm{SO}_{2}$ can be
Table 1 Weekly average values for measurements of $\mathrm{SO}_{2}, \mathrm{NO}_{2}$ and $\mathrm{O}_{3}\left(\mu \mathrm{g} \mathrm{m}^{-3}\right)$

\begin{tabular}{lllll}
\hline Sampling date & 14-28 March 2011 & 1-15 June 2011 & 17-31 October 2011 & 2-16 January 2012 \\
\hline $\mathrm{SO}_{2}\left(\mu \mathrm{g} \mathrm{m}^{-3}\right)$ & & & & \\
Minimum & 11.77 & 13.94 & 14.87 & 30.49 \\
Maximum & 72.92 & 45.91 & 46.43 & 84.32 \\
Average $\pm \mathrm{SD}$ & $46.91 \pm 19.36$ & $27.92 \pm 9.79$ & $32.57 \pm 10.09$ & $58.20 \pm 14.05$ \\
$\mathrm{NO}_{2}\left(\mu \mathrm{g} \mathrm{m}^{-3}\right)$ & & & & \\
$\mathrm{Minimum}$ & 17.44 & 8.11 & 7.44 & 30.42 \\
Maximum & 44.5 & 36.2 & 63.53 & 66.8 \\
Average $\pm \mathrm{SD}$ & $25.66 \pm 7.58$ & $20.79 \pm 10.19$ & $30.75 \pm 13.84$ & $41.04 \pm 9.54$ \\
$\mathrm{O}_{3}\left(\mu \mathrm{g} \mathrm{m}^{-3}\right)$ & & & & 11.02 \\
Minimum & 35.12 & 52.49 & 22.29 & 25.93 \\
Maximum & 72.64 & 81.08 & 33.26 & $17.84 \pm 3.90$ \\
Average $\pm \mathrm{SD}$ & $50.73 \pm 10.15$ & $66.35 \pm 7.17$ & $25.36 \pm 2.86$ & \\
\hline
\end{tabular}



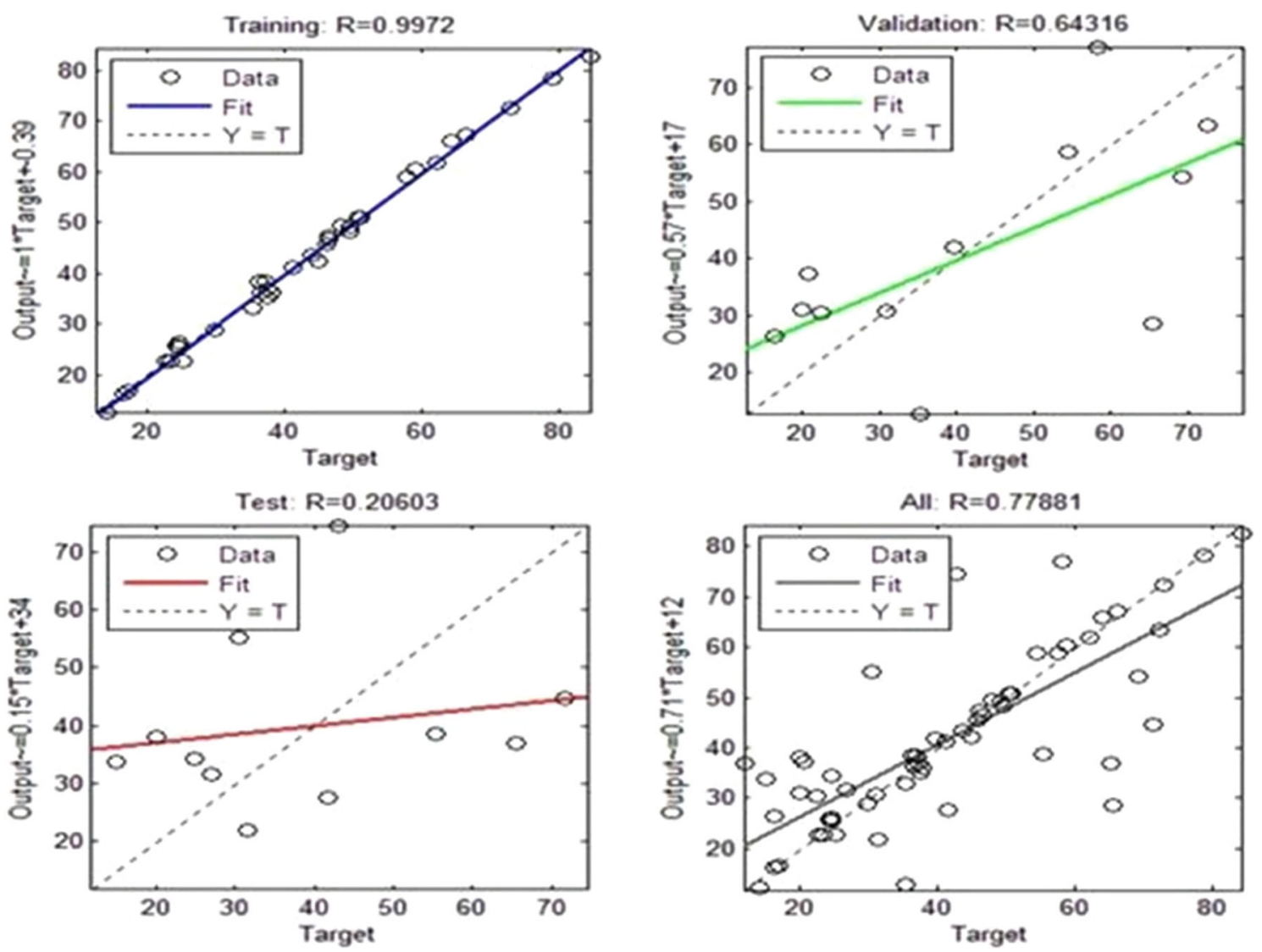

Fig. 3 Plot of training, validation, testing and all $\mathrm{R}$

clearly described in these figures. These plots of parameters are very informative for presenting the $\mathrm{SO}_{2}$ relation and the input parameters. These plots of parameters show that the relations are highly nonlinear and suggest the employment of intelligent systems to predict the sulphur dioxide.

The membership functions are the process of fuzzification and converting a crisp value into a fuzzy one. Many measurable quantities such as wind speed, temperature, moisture and $\mathrm{NO}_{2}$ are considered to be crisp and deterministic; however, in real life they are not deterministic at all. They carry considerable uncertainties. When the uncertainty increases because of ambiguity, impression and vagueness, then the parameters are considered to be fuzzy and can be represented by MFs. The MFs are defined by linguistic terms such as very low, low, average, high and very high. In this study, Gaussian MFs were employed to obtain the membership degrees. Figure 6 illustrates the graphical representations of fine-tuned membership functions for the wind speed, temperature, moisture and $\mathrm{NO}_{2}$.

A neuro-Fuzzy model consists of many logical rules, which is based on qualitative knowledge. Fuzzy if-then rules and fuzzy reasoning are the backbone of fuzzy inference systems, and they are the most important modelling tool in fuzzy set theory. Fuzzy modelling means representing the characteristics of a process by a set of fuzzy implications with input variables, state and output variables. The relations of these characteristics are presented by fuzzy rules. The rules are the linguistic relationships, mapping the inputs to outputs relations. The fuzzy rules can identify any characteristic in a space by membership functions and linguistic labels. A linguistic variable differs from a numerical variable in that its values are not numbers but words or sentences. For instance, air pressure is a linguistic variable and a term set such as very low, low, moderate and high can identify it. Similarly, the other linguistic variables and their term sets are given below.

$$
\begin{aligned}
& \mu\left(x_{1}\right): T(\text { Air_pressure })=\{\text { very_low, low, moderate, high }\} \\
& \mu\left(x_{2}\right): T(\text { Temperature })=\{\text { very_low, low, normal, high }\} \\
& \mu\left(x_{3}\right): T(\text { Moisture })=\{\text { very_low, low, average, high }\} \\
& \mu\left(x_{4}\right): T(\text { Rain_fall })=\{\text { dry, average }, \text { humid }, \text { high, very_high }\} \\
& \mu\left(x_{5}\right): T(\text { Wind_speed })=\{\text { quiet }, \text { moderate, active, windy }\} \\
& \mu\left(x_{6}\right): T\left(\mathrm{NO}_{2}\right)=\{\text { acceptable, average, high, very_high }\} \\
& \mu\left(x_{7}\right): T(\text { Ozone })=\{\text { acceptable, average, high, very_high }\}
\end{aligned}
$$

Fuzzy rule-based system is one of the most useful approaches modelling the complex systems because it 

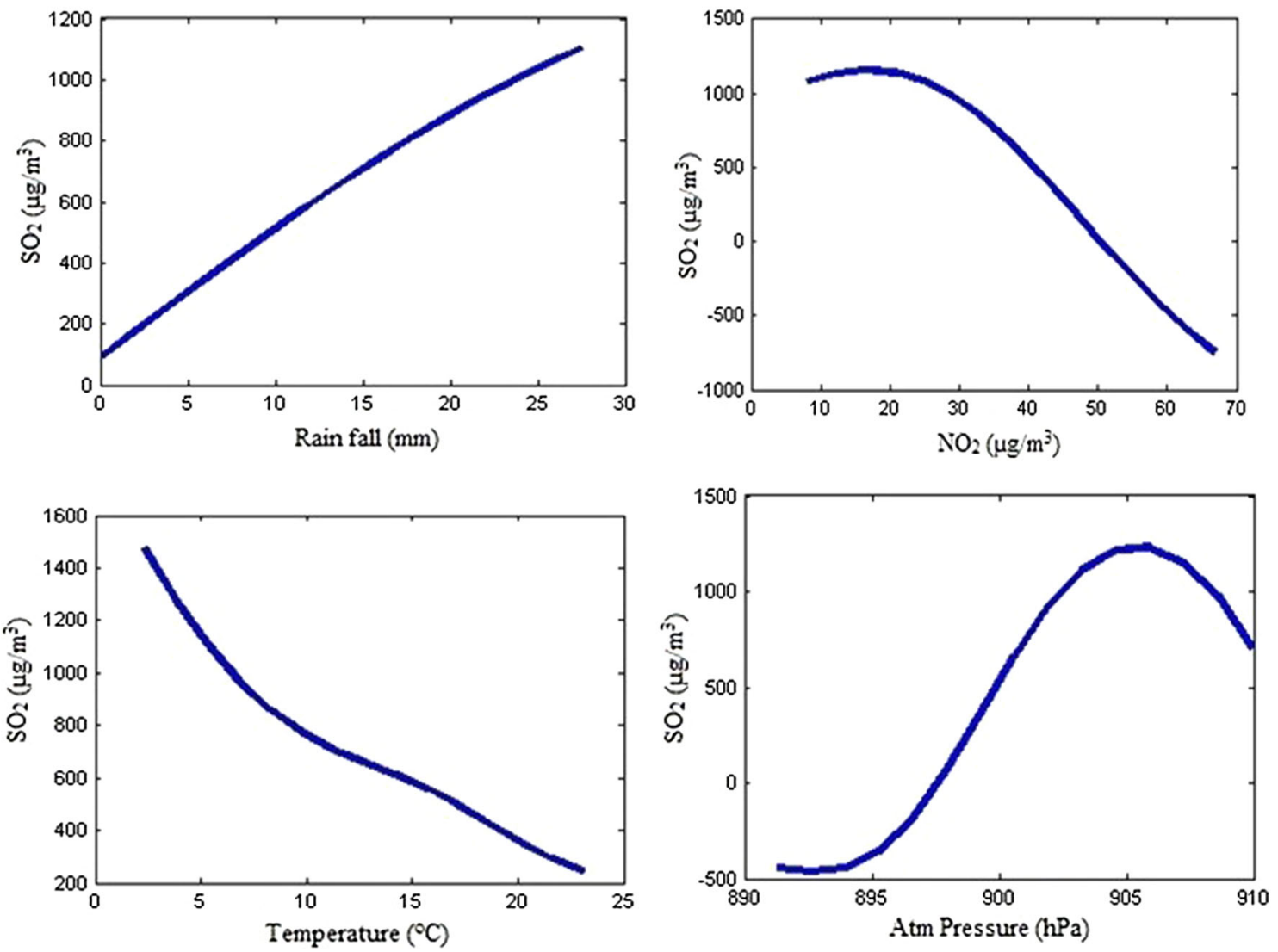

Fig. 4 One-dimensional universes of $\mathrm{SO}_{2}$ concentration and input parameters were presented using 42 data sets
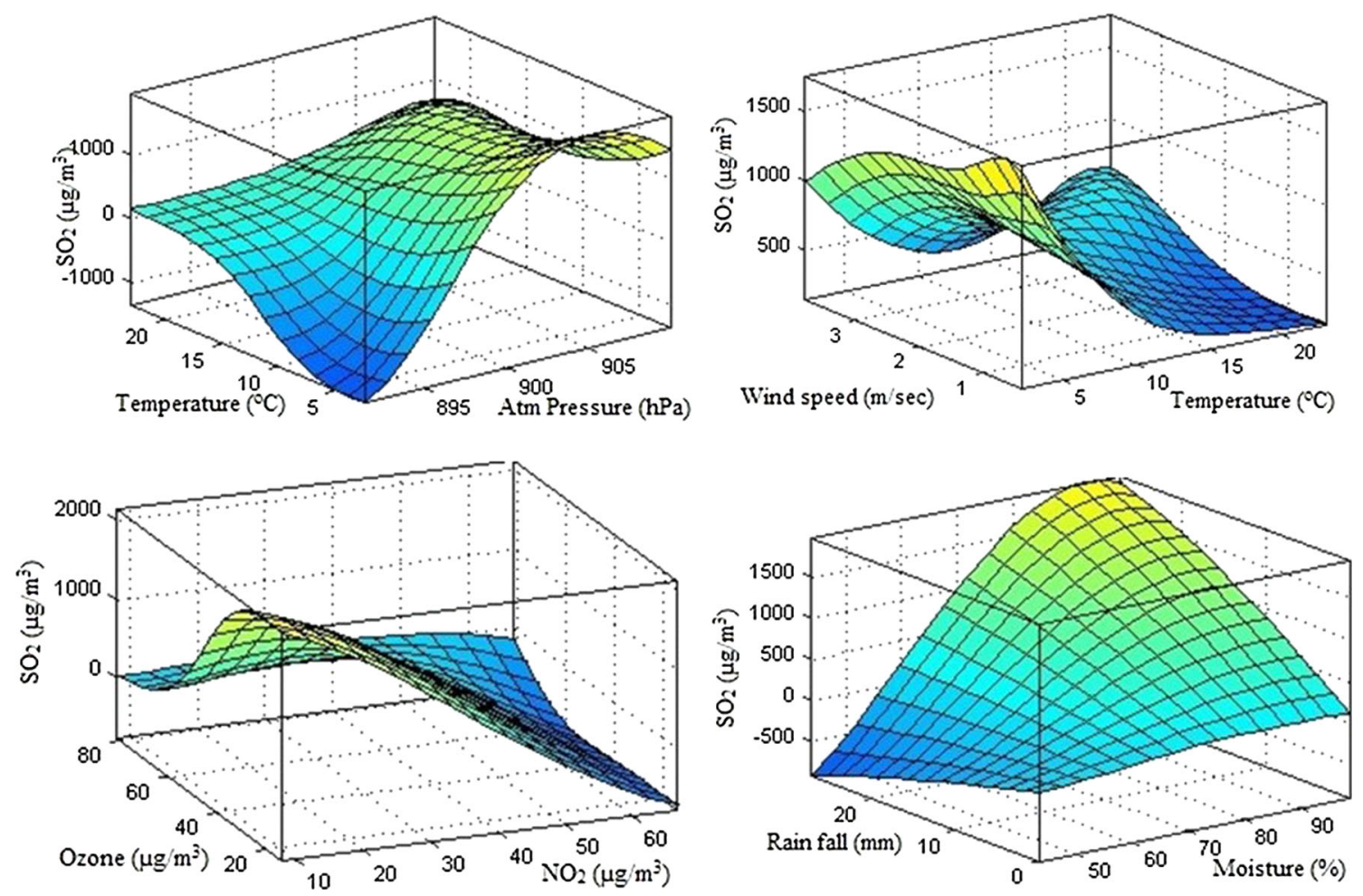

Fig. 5 Two-dimensional plots of input parameters and $\mathrm{SO}_{2}$ concentration were presented using 42 data sets 

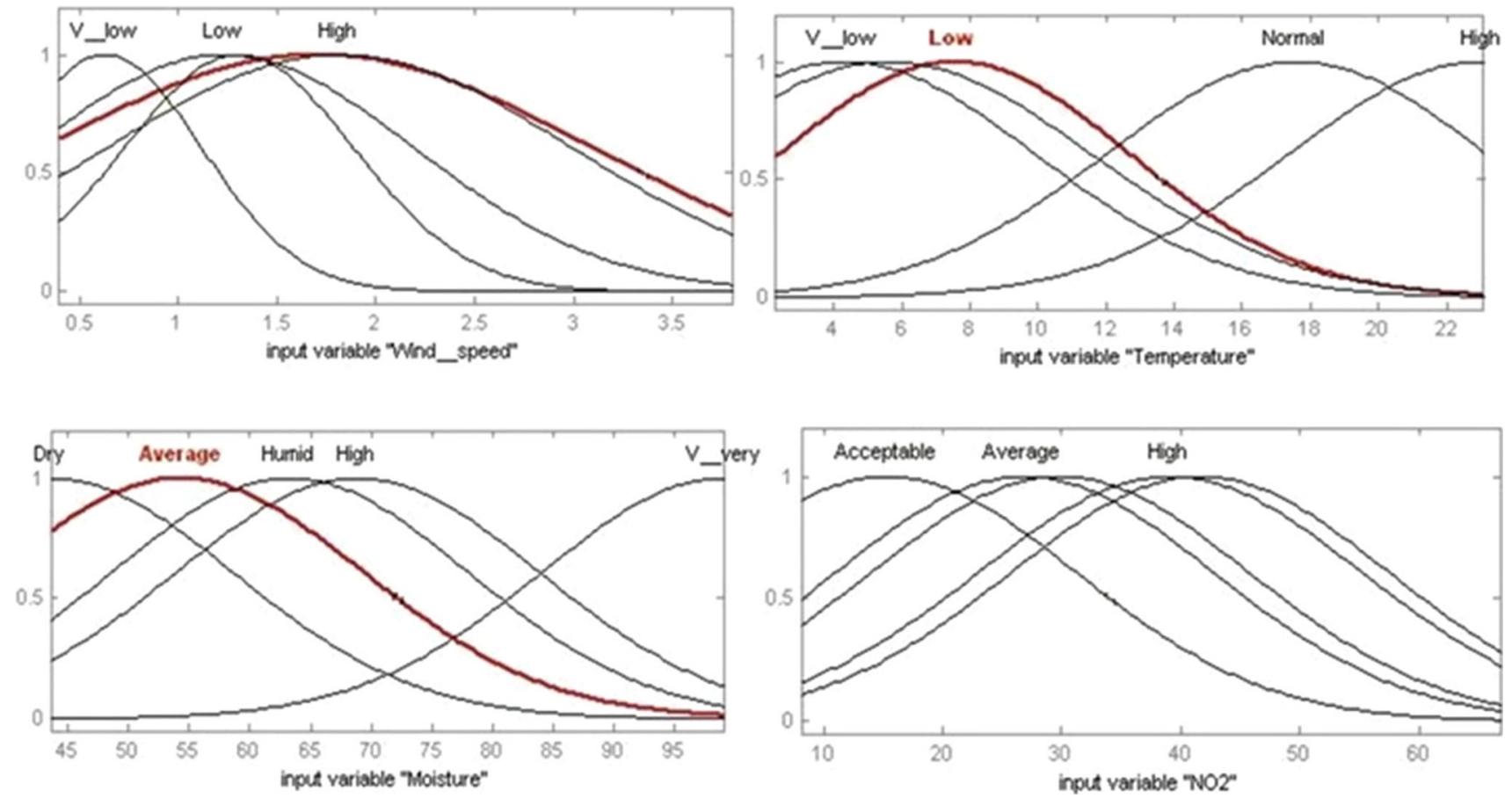

Fig. 6 Gaussian MFs and fuzzy labels of wind speed, temperature, moisture and $\mathrm{NO}_{2}$ were presented using 42 data sets

makes use of linguistic variables as its antecedents and consequents. The rules are based on natural language representation, which are based on fuzzy sets and fuzzy logic. The outputs $\left(Z_{k}\right)$ of $\mathrm{SO}_{2}$ concentration are first-order polynomials, and hence, the resulting neuro-fuzzy inference system is called a first-order Sugeno fuzzy model. The adaptive network under consideration has only one overall output, ' $\mathrm{SO}_{2}$ ', which is the vector of input variables, and $f$ is the overall function implemented by the adaptive network. Because the antecedent part of the fuzzy rule is constructed by the connective 'and', the degrees of compatibility between fuzzy sets is called the "firing strength' of the fuzzy rule. This represents the degree to which the antecedent part of the rule is satisfied.

Fuzzy reasoning, also known as approximate reasoning, is an inference procedure that derives conclusions from a set of if-then rules and fact base. Figure 7 depicts the fuzzy reasoning of $\mathrm{SO}_{2}$. Fuzzy rules are constituted from fuzzy linguistic variables and their term sets. However, the outcomes of an ANFIS model should be crisp values. The model in this study is a multiple rules and antecedents fuzzy model. The interpretation of multiple rules is usually taken as the union of the fuzzy relations corresponding to the fuzzy rules. Fuzzy rules are constituted from fuzzy linguistic variables and their term sets. Taylan and Taskin (2003) pointed that in a fuzzy model, the number of rules has an essential effect on how fine a control level can be achieved on a fuzzy modelling system. The size of inputoutput data is 82 data readings from Konya city in Turkey, which are enough to establish the ANFIS model and finetune the membership functions.

The error tolerance was fixed to 0.001 for training the algorithm. This ANFIS model has the average training error of $3.21 \%$ and the average checking error of $3.04 \%$. After 500 epochs, the root-mean-square errors (RMSE) for training data were determined to be 1.656 , and for checking data, it is 1.82 . The error percentage of training and checking data of ANFIS outcomes versus the actual outcomes is illustrated in Table 2. This table also presents the outcomes of neural network model against the actual outcomes of $\mathrm{SO}_{2}$ for certain input parameters.

The testing procedure for model validation was carried out, and a part of outcomes is presented in Table 2. For each input parameter, 35 data were used for testing the ANFIS and neural network model. The actual outcomes of $\mathrm{SO}_{2}$ versus ANFIS model outcomes and neural network are illustrated in Fig. 8. This figure presents that there is variation in the distribution of $\mathrm{SO}_{2}$, and the variation of neural network model is apparently higher than the ANFIS model. The trend shows that the amount of $\mathrm{SO}_{2}$ is increasing by time.

\section{Comparing the performance of developed models}

In this study, an ANFIS model together with a neural network was developed. The ANFIS model has five rules. The performance of the developed models was assessed 


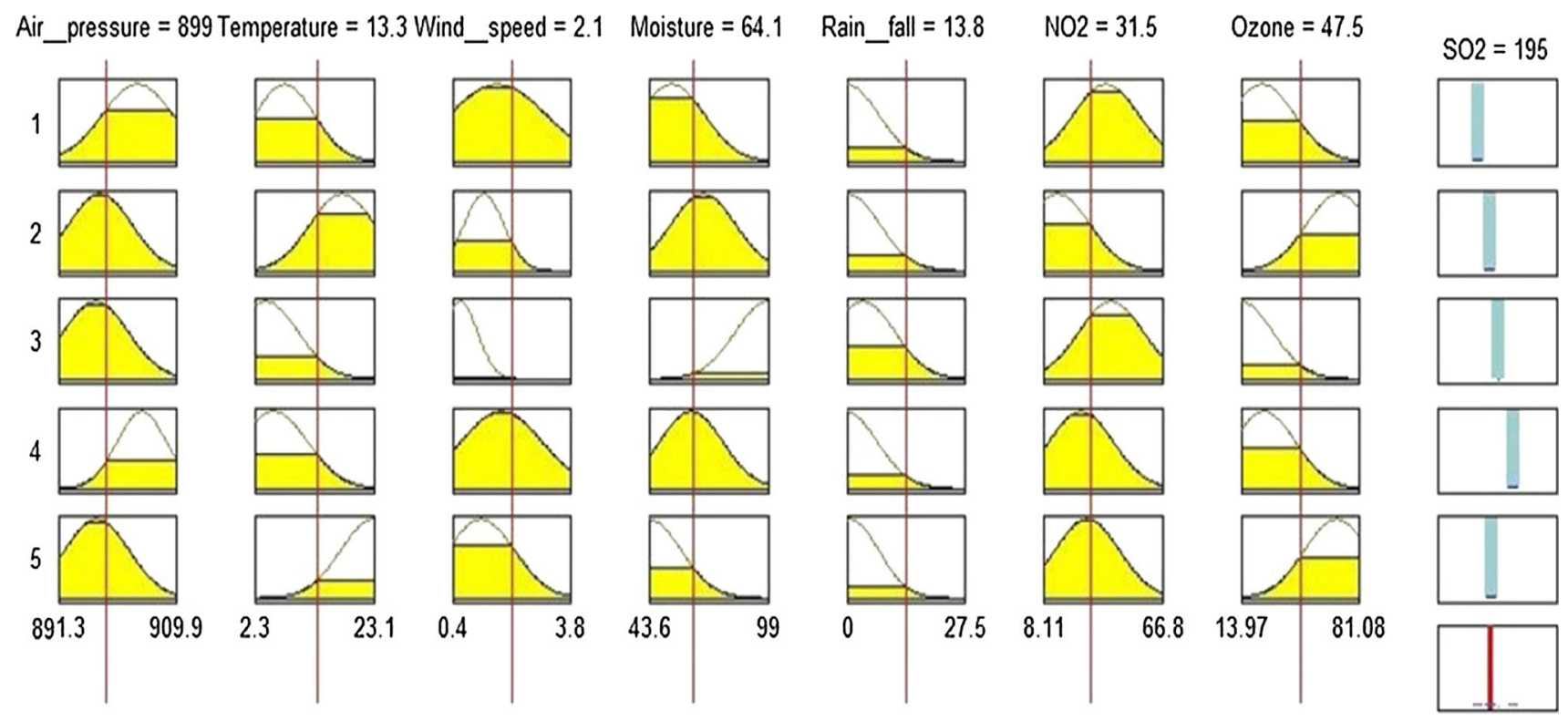

Fig. 7 Fuzzy inference system for $\mathrm{SO}_{2}$ estimation

Table 2 Validation of neural network and ANFIS outcomes versus actual $\mathrm{SO}_{2}$ outcomes

\begin{tabular}{|c|c|c|c|c|c|c|c|c|c|}
\hline $\begin{array}{l}\text { Atm pressure } \\
(\mathrm{hPa})\end{array}$ & $\begin{array}{l}\text { Temperature } \\
\left({ }^{\circ} \mathrm{C}\right)\end{array}$ & $\begin{array}{l}\text { Wind speed } \\
\left(\mathrm{m} \mathrm{s}^{-1}\right)\end{array}$ & $\begin{array}{l}\text { Moisture } \\
(\%)\end{array}$ & $\begin{array}{l}\text { Rain fall } \\
(\mathrm{mm})\end{array}$ & $\begin{array}{l}\mathrm{NO}_{2} \\
\left(\mu \mathrm{g} \mathrm{m}^{-3}\right)\end{array}$ & $\begin{array}{l}\text { Ozone } \\
\left(\mu \mathrm{g} \mathrm{m}^{-3}\right)\end{array}$ & $\begin{array}{l}\text { Actual } \\
\text { outcomes } \\
\left(\mathrm{SO}_{2}\right)\end{array}$ & $\begin{array}{l}\mathrm{NN} \\
\text { outcomes } \\
\left(\mathrm{SO}_{2}\right)\end{array}$ & $\begin{array}{l}\text { ANFIS } \\
\text { outcomes } \\
\left(\mathrm{SO}_{2}\right)\end{array}$ \\
\hline 909.9 & 2.3 & 1 & 83.5 & 0 & 20.05 & 50.97 & 56.82 & 52.23 & 55.62 \\
\hline 909.4 & 5.3 & 0.5 & 73.5 & 0 & 44.5 & 46.21 & 61.05 & 61.97 & 62.31 \\
\hline 906.8 & 8.5 & 1 & 61.5 & 0 & 21.32 & 46.25 & 61.11 & 56.22 & 63.24 \\
\hline 903 & 12.8 & 1 & 48 & 0 & 32.21 & 35.12 & 66.98 & 69.03 & 68.52 \\
\hline 900 & 11 & 0.9 & 64.5 & 1.1 & 33.92 & 43.6 & 27.82 & 25.53 & 28.6 \\
\hline 897.1 & 11.4 & 1.2 & 65 & 1.2 & 38.37 & 68.54 & 48.92 & 48.76 & 49.16 \\
\hline 896.6 & 8.4 & 1.3 & 76.1 & 0 & 23.06 & 72.64 & 34.09 & 35.16 & 33.42 \\
\hline 896.9 & 6.8 & 3.9 & 88.8 & 2.4 & 19.75 & 58.21 & 49.47 & 51.79 & 48.85 \\
\hline 901.3 & 3.5 & 3.8 & 81.9 & 0.4 & 21.92 & 52.77 & 43.8 & 46.61 & 44.56 \\
\hline 901.2 & 2.3 & 1.8 & 75 & 0.1 & 23.37 & 44.16 & 36.33 & 47.74 & 38.65 \\
\hline 900.4 & 3.2 & 2.6 & 70.8 & 0 & 24.63 & 60.55 & 49.28 & 39.374 & 50.16 \\
\hline 904.5 & 5 & 1.9 & 61.3 & 0 & 20.72 & 43.66 & 65.49 & 75.34 & 68.65 \\
\hline 902.8 & 7.8 & 1.2 & 53.4 & 0 & 22.85 & 37.91 & 24.97 & 24.58 & 25.78 \\
\hline 901.1 & 8.3 & 1.3 & 56.1 & 0 & 20.92 & 50.75 & 43.72 & 48.84 & 45.23 \\
\hline 901.1 & 9.3 & 1 & 64.4 & 0 & 17.44 & 49.71 & 71.66 & 70.59 & 72.16 \\
\hline 897.7 & 18 & 1.2 & 62.8 & 0.1 & 10.57 & 69.84 & 16.3 & 15.28 & 17.85 \\
\hline 897.8 & 17.6 & 1.5 & 68.9 & 0.2 & 15.36 & 69.56 & 27.71 & 27.71 & 29.4 \\
\hline 898.8 & 18.3 & 1.9 & 66.1 & 1.7 & 8.11 & 64.5 & 34 & 30.88 & 35.67 \\
\hline 898.7 & 16.4 & 1.4 & 75.9 & 1.6 & 10.32 & 64.62 & 37.38 & 41.56 & 38.64 \\
\hline$\ldots$ & $\ldots$ & $\ldots$ & $\ldots \ldots$ & $\ldots$ & $\ldots \ldots$ & $\ldots$. & $\ldots$. & $\ldots$. & $\ldots$ \\
\hline
\end{tabular}

and compared based on the average predictive error and the residual ranges. The average prediction error was computed using Eq. 12.
Average Prediction Error \%

$$
=\frac{\sum \mid \text { Actual outcome }- \text { Predicted outcome } \mid}{\sum \text { Actual outcome }} \times 100
$$



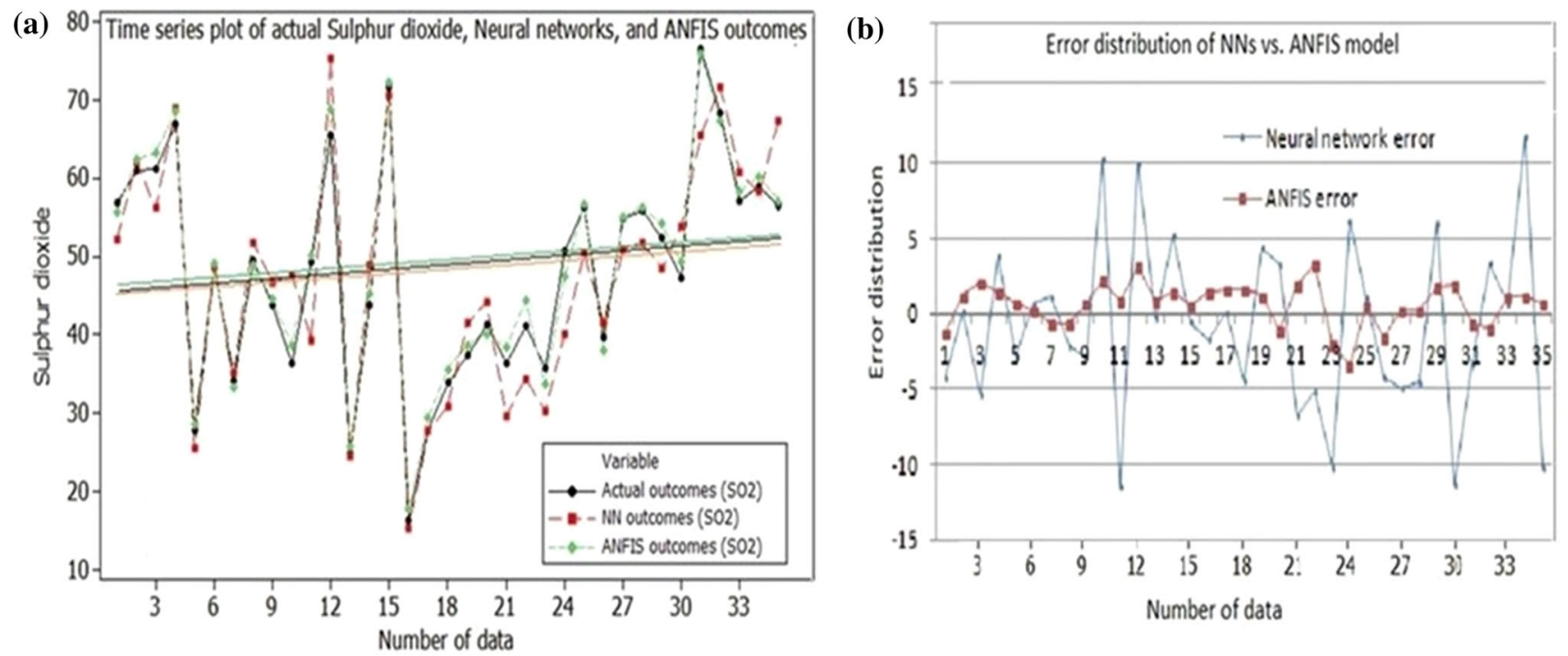

Fig. 8 a Actual outcomes of $\mathrm{SO}_{2}$ versus estimated $\mathrm{SO}_{2}$ of ANFIS and $\mathrm{ANN}$ model outcomes; $\mathbf{b}$ the residual of actual $\mathrm{SO}_{2}$ outcomes vs estimated $\mathrm{SO}_{2}$ of ANFIS and ANN

The average of the prediction error associated with the ANFIS models with five rules was found to be 2.81 , and $9.79 \%$ average error of the neural network model was determined. Clearly, the ANFIS models with five rules outperformed the neural network model. The error distribution of neural network and ANFIS model outcomes is presented in Fig. 8.

The residuals of each of the developed models were obtained by computing the difference between the actual and the predicted values of $\mathrm{SO}_{2}$ as shown in Fig. 4. The residuals range from -11.44 to 11.76 for the neural network model, whereas the ranges were, respectively, -0.37 to 3.33 when the ANFIS models with five rules were employed. The residuals of neural network model and ANFIS model are presented in Fig. 8. The ANFIS model with five rules was, by far, the most accurate model for predicting $\mathrm{SO}_{2}$ among the examined ones.

To assess the performance of the examined models in terms of predicting $\mathrm{SO}_{2}$ based on new parameter values, a confirmation data set was obtained using new combinations of the factor and the results are displayed in Table 2. Also given are the predicted values obtained based on the ANFIS model with five rules and the neural network model together with the error values. These data were used to estimate the average prediction error of each model. As the error percentage associated with the ANFIS model (2.81\%) was smaller than the value obtained based on the neural network one $(9.79 \%)$, the superiority of the ANFIS model in approximating the relationship between the $\mathrm{SO}_{2}$ was confirmed.

\section{Conclusion}

Air pollution has an effete on disturbing in Konya Centrum during last years. Mostly two significant air pollutants factors, $\mathrm{SO}_{2}$ and $\mathrm{PM}$, are affecting the human health and environment quality of the Konya city (Kunt and Dursun 2010). The main sources of the pollutants are because of using unsuitable fossil fuels for heating system during winter period need high priority action on it. The air pollutant sources include the public use of fossil for heating system during the very cold winter period as well as use in industrial region like chrome-magnesite factory, Konya cement factory, Konya sugar production factory and several industries in the Konya-organized industrial region. The second source is road vehicles activity including all forms of the transportation vehicles. This is also priority for action within the context of this study but not in terms of national action (Dursun and Ucan 2009).

There is a great development in Konya city centre and around with this development; air pollution is increasing parallel to population and industrial development. Topographic position and meteorological rules cause increase in air pollution mostly in winter period. This study purpose is to find the relation between the districts meteorological factors with the air pollution of city centre $\left(\mathrm{SO}_{2}, \mathrm{NO}_{2}\right.$ and ozone). Today, air polluters change day by day in atmosphere; some of them can be collected at different layers of the atmosphere, becoming more harmful and moving to other districts (Dursun 1997). In the future years, air pollution will be at a dangerous level so that more detail work must be done with developing scientific knowledge.

An air pollution concentration in any area depends on the amount of factor that brings out the pollution but also the 
meteorological factors and topographic structure of area (Dursun 1997). If the topographic structure of Konya city were searched with wind blowing ways, it would be seen that the north and west sides are closed with high mountains, and south and east sides are unobstructed. Air activity is related to the geographic location and topographic situation of Centrum [http://tr.wikipedia.org/ wiki/Anadolu (Accessed, 08 December 2013)]. Konya has an intensive population and industry. It has surrounded with mountains and shaped like earthenware pot so that it has increase in air pollution problem. Investigation area is placed in Konya city centre and in municipality region. Searching air pollution parameter according to the meteorological data is necessary for preventing the repetition of same problems.

There have been actions taken to reduce the levels of pollution from the stationary sources, but the results are still not enough. In terms of transportation sources, the issue is national in scope and is being dealt with there. Until the industries comply, the situation will not improve enough quality to reduce contribution margin ratio in the air pollution level. Actions that will continue are monitoring of the air quality and continuing pressure on the industries to reduce the pollution level and increase the ambient air quality. New industrial developments should be restricted to well-defined areas in the city and should be using the most new technology and using new environment-friendly energy sources.

In conclusion, information of earlier values of sulphur dioxide $\left(\mathrm{SO}_{2}\right)$ concentrations is important in order to estimate the future pollution values. In present study, $\mathrm{SO}_{2}$ concentrations in Konya city centre are predicted using ANN approach. During the training and test period, the errors of ANN and ANFIS are depending between about 10 to -10 and 3 to -3 , respectively. The results illustrated that artificial neural networks offer a valuable method for air pollution management but ANFIS predictions were more convenient. It is remarkable that after training a neural network and ANFIS with 2011 and 2012 data, reasonably good predictions are able to generate. This result can be of great importance in order to run an operational model to predict $\mathrm{SO}_{2}$ pollutant concentrations.

The purpose of this study has been to demonstrate the use of the artificial intelligence (AI) methods such as neural networks and fuzzy logic for air quality prediction and its distribution. Generally, the trend of fuzzy set and systems is towards the compilation of different forms of knowledge representation for the best identification and control of ill-defined complex systems. The two new paradigms 'artificial neural networks and fuzzy systems' try to understand a real-world system starting from the very fundamental sources of knowledge. Intelligent systems such as neural networks and genetic algorithms might also be the subject of future studies. This method can be supported by the flexibility of fuzzy set and systems.

Since the ANFIS is an adaptive network which permits the usage of ANN topology together with fuzzy logic, it includes the characteristics of both methods and also eliminates some disadvantages of their lonely used case. Therefore, this technique is capable of handling complex and nonlinear problems. Even if the targets are not given, the ANFIS may reach the optimum result rapidly. In addition, there is no vagueness in ANFIS as opposed to ANNs. Moreover, the learning duration of ANFIS is very short compared to ANN-based models. It implies that ANFIS may reach to the target faster than ANN (Yetilmezsoya et al. 2011).

Air quality is taken as an important appearance of the quality of human life guide for sustainable development in many regions of the world. Air pollution control strategies have been taken seriously, on both global and local scales and governments have taken important steps for air pollution control. Air pollution management is usually developed from awareness, demands and realization of needs of the community and decision makers. Air pollution management requires capacity building, groundbased monitoring systems and networks for proper operation and strategic decision support. It also requires quality assurance and quality control, modelling tools and institutional capabilities for implementation. Finally, the main goal of ANFIS modelling approach is to predict air quality index for providing online information to immediate assessment of air quality for public health in a more intelligent way. It can be considered useful, reliable and suitable method for consideration by authorities in air quality evaluation and ruling.

Acknowledgments Authors would like to thank Selcuk University (BAP) for the financial support of this study with Project Number BAP-10401028.

\section{References}

Alkasassbeh M, Sheta AF, Faris H, Turabieh H (2013) Prediction of PM10 and TSP air pollution parameters using artificial neural network autoregressive, external input models: a case study in salt, Jordan. Middle East J Sci Res 14:999-1009

Aw J, Kleeman M (2003) Evaluating the first-order effect of intra annual temperature variability on urban air pollution. J Geophys Res 108(D12):5047-5068

Barnett AG, Williams GM, Schwartz J, Best TL, Neller AH, Petroeschevsky AL (2006) The effects of air pollution on hospitalizations for cardiovascular disease in elderly people in Australian and New Zealand cities. Environ Health Perspect 114:1018-1023

Bertoni G, Tappa R, ve Allegrini I (2000) Assessment of a new device for the monitoring of benzene and other volatile aromatic compounds in the atmosphere. Annali di Chim 90:249-263

Cacciola M, Pellicanò D, Megali G, Lay-Ekuakille A, Versaci M, Morabito FC (2013) Aspects about air pollution prediction on urban environment. 4th Imeko TC19 symposium on environmental instrumentation and measurements protecting environment, climate changes and pollution control, June 3-4, 2013, Lecce, Italy, pp 15-20

Chelani AB, Rao CVC, Phadke KM, Hasan MZ (2002) Prediction of sulphur dioxide concentration using artificial neural networks. Environ Model Softw 17:161-168

Curtis L, Rea W, Smith-Willis P, Fenyves E, Pan Y (2006) Adverse health effects of outdoor air pollutants. Environ Int 32:815-830

Deutsch A, de la Parra RB, de Boer RJ (eds) (2008) Mathematical modeling of biological systems, volume II: epidemiology, evolution 
and ecology, immunology, neural systems and the brain, and innovative mathematical methods. Springer, Birkauser, pp 406

Dursun S (1997) Effects of topographical structure around Samsun city on air pollution in the region, 20th geology symposium, Konya, pp 211-215

Dursun S, Ucan HN (2009) Air pollution dimensions of Konya City and environmental effects 15th international symposium on environmental pollution and its impact on life in the mediterranean region October 7-11, Bari, Italy

Dursun S, Onder S, Acar R, Direk M, Mucehver M (2012) Effect of environmental and socioeconomically change on agricultural production in Konya region 2012 international conference on applied life sciences (ICALS), Turkey, 10-12 September 2012, pp 1-11

Fallahpour AR, Moghassem AR (2013) Yarn strength modelling using adaptive neuro-fuzzy inference system (ANFIS) and gene expression programming (GEP). J Eng Fibers Fabr 8:6-18

Fuller AD (1995) Neural fuzzy systems. Abo Akademi University, Abo

Gardner MW, Dorling SR (2000) Statistical surface ozone models: an improved methodology to account for nonlinear behavior. Atmos Environ 34:21-34

Goyal SK, Ghatge SV, Nema P, Tamhane SM (2006) Understanding urban vehicular pollution problem vis-a-vis ambient air quality- case study of a megacity (Delhi, India). Environ Monit Assess 119:557-569

Güçlü G, Dursun S (2010) Hybrid modelling approach for improving prediction performance of a mathematical model in a large-scale wastewater treatment plant. Bioprocess Biosyst Eng 33:1051-1058

Hájek P, Olej V (2009) Intuitionistic Hierarchical Fuzzy Inference Systems Design for Air Quality Modelling. In: Mastorakis N et al (eds) Proceedings of the 5th International Conference on Energy, Environment, Ecosystems and Sustainable Development, (EEESD’09), Greece, pp 89-94

Jang JSR, Sun CT, Mizutani E (1997a) Neuro-fuzzy and soft computing: a computational approach to learning and machine intelligence. Prentice Hall, NJ, p 587

Jang JSR, Sun CT, Mizutani E (1997b) Neuro-fuzzy and soft computing. Prentice Hall, NJ, p 1081

Jorquera H, Perez R, Cipriano A, Espejo A, Letelier MV, Acuna G (1998) Forecasting ozone daily maximum levels at Santiago, Chile. Atmos Environ 32:3415-3424

Kadiyala A, Kumar A (2012) Guidelines for operational evaluation of air quality models. Lambert Academic Publishing GmbH \& Co, Germany, p 123. ISBN 978-3-8465-3277-5

Kadiyala A, Kumar A (2013) Artificial intelligence: emerging approaches for environmental data analysis, EM, 4- 5, Aug. (invited paper)

Kadiyala A, Kaur D, Kumar A (2013) Development of hybrid genetic algorithm based neural networks using regression trees for modeling air quality inside a public transportation bus. J Air Waste Manag Assoc 63:205-218

Khan FI, Sadiq R (2005) Risk-based prioritization of air pollution monitoring using fuzzy synthetic evaluation technique. Environ Monit Assess 105:261-283

Khare M, Nagendra SM (2007) Vehicular pollution, artificial neural networks in vehicular pollution modelling. SCI 41:7-24

Kunt F, Dursun Ş (2010) The effect of some meteorological factors to the air pollution in center of Konya. In: International Conference on Air Pollution and Control, Ankara 25-27 October

Kunt F, Dursun S (2012) Measurement of atmospheric ozone concentration using passive sampler method in Konya city centre during 2012 winter period. International conference on "Towards future sustainable development" Shkodër, Albania 16-17 November 2012 Abstract Book, p 192

Lin CT (1996) Neural fuzzy systems: a neuro-fuzzy synergism to intelligent, Prentice Hall PTR, New Jersey, p 797

Moumeni B, Golmai SH, Palangi JA (2013) Comparison of using different systems of artificial intelligence in subsurface water level prediction (case study: paddy fields of plain areas between Tajan and Nekaroud Rivers, Mazandaran, Iran). J Novel Appl Sci 2:375-381

Nie J (1995) Constructing fuzzy model by self-organizing counterpropagation network. IEEE Trans Syst Man Cybern 25(6):963-970

Onkal-Engin G, Demir I, Hiz H (2004) Assessment of urban air quality in Istanbul using fuzzy synthetic evaluation. Atmos Environ 38:3809-3815

Ordieres JB, Vergara EP, Capuz RS, Salazar RE (2005) Neural network prediction model for fine particulate matter $\left(\mathrm{PM}_{2.5}\right)$ on the US-Mexico border in El Paso (Texas) and Ciudad Jua 'rez (Chihuahua). Environ Model Softw 20:547-559

Ozden O (2005) Master of Science thesis: monitoring of air quality by use of passive samplers. Anadolu University, Graduate School of Natural and Applied Sciences, Environmental Engineering Program, Eskişehir, Turkey

Öztürk AI, Arslan M, Toros H, Dursun S (2013) Air quality forecast study in Istanbul. 13th EMS annual meeting \& 11th European Conference European Meteorological Society, Reading Un. UK

Perez P, Trier A (2001) Prediction of NO and NO2 concentrations near a street with heavy traffic in Santiago, Chile. Atmos Environ 35:1783-1789

Perez P, Trier A, Reyes J (2000) Prediction of $\mathrm{PM}_{2.5}$ concentrations several hours in advance using neural networks in Santiago, Chile. Atmos Environ 34:1189-1196

Rani BK, Govardhan A (2013) Rainfall prediction using data mining techniques-a survey. Comput Sci Inf Technol 3:23-30

Rawat K, Burse K (2013) A soft computing genetic-neuro fuzzy approach for data mining and its application to medical diagnosis. Int J Eng Adv Technol 3:409-411

Romieu I, Lugo MC, Velasco SR, Sanchez S, Meneses F, Hermandez M (1992) Air pollution and school absenteeism among young children in Mexico City. Am J Epidemiol 136:1424-1531

Savić M, Mihajlović I, Živković Ž (2013) An Anfis—based air quality model for prediction of $\mathrm{SO}_{2}$ concentration in urban area. Serb J Manag 8:25-38

Soni A, Shukla S (2012) Application of neuro-fuzzy in prediction of air pollution in urban areas. IOSR J Eng 2:1182-1187

Sowlat MH, Gharibi H, Yunesian M, Mahmoudi MT, Lotfi S (2011) A novel, fuzzy-based air quality index (FAQI) for air quality assessment. Atmos Environ 45:2050-2059

Sugeno M, Takagi T (1983) Multi-dimensional fuzzy reasoning. Fuzzy Sets Syst 9(2):313-325

Taylan O (2013a) Prediction of air quality for sustainable environment by artificial intelligent techniques. Energy Educ Sci Technol Part A Energy Sci Res 31:1635-1652

Taylan O (2013b) Assessing air quality in Jeddah by modeling suspended PM10 concentration. J Int Environ Appl Sci 8:326-335

Taylan O, Taskin H (2003) Fuzzy modeling of a production system. J Nav Sci Eng 1:1-13

Yay OD, Özden Ö, Altuğ H, Gaga E, Erdemir G, Örnektekin S, Döğeroğlu T, Meliefste K, Doorn WV (2008) Preliminary assessment of air quality in İskenderun-Payas Strict with passive sampling. International Conference of Air Pollution and Control-2008, 22-25 Ekim, Hatay

Yetilmezsoya K, Fingas M, Fieldhouse B (2011) An adaptive neurofuzzy approach for modeling of water-in-oil emulsion formation. Colloids Surf A Physicochem Eng Aspects 389:50-62

Yıldırım Y, Bayramoglu M (2006) Adaptive neuro-fuzzy based modelling for prediction of air pollution daily levels in city of Zonguldak. Chemosphere 63:1575-1582

Zemp E, Elsasser S, Schindler C, Kunzli N, Perruchoud A, Domenighetti G (1999) Long-term ambient air pollution and respiratory symptoms in adults (SAPALDIA study). Am J Respir Crit Care Med 159:1257-1266

Zounemat-Kermani M, Scholz M (2013) Computing air demand using the Takagi-Sugeno model for dam outlets. Water 5:1441-1456 